\title{
MAX HORKHEIMER: TEORÍA TRADICIONAL \\ Y TEORÍA CRÍTICA. LA SINGULARIDAD \\ EPISTEMOLÓGICA PARA LA \\ TRANSFORMACIÓN DE LA SOCIEDAD
}

JORGe ÁvILA

El juicio categórico es típico de la sociedad preburguesa: así son las cosas, el hombre no puede cambiar nada. Las formas hipotética y disyuntiva de juicio tienen su lugar propio especialmente en el mundo burgués: bajo ciertas circunstancias se puede producir este efecto, las cosas son o bien así o de otro modo.

La teoría crítica declara: las cosas no tienen que ser necesariamente así, los hombres pueden transformar el ser, ahora están dadas las condiciones para ello.

MAX HORKHEIMER

El mayor interés de este ensayo de 1937 (Teoría tradicional y teoría crítica) es delinear el pensamiento crítico social en contraste con las teorías del pasado, a partir del reconocimiento de que la esencia práctica, aquella generalidad que propicia una particular forma de teoría, son las condiciones económicas de determinado momento histórico. Tal punto de partida marxiano se afina inmediatamente por la relevancia del capitalismo tardío como teatro histórico de la teoría crítica. Para desbordarse desde la crítica de la economía política de El capital hacia el proceso global de crítica de la burguesía, su caudal se incrementa con la investigación de la sociología, del psicoanálisis y de la tradición dialéctica. La clave de esta original síntesis, desde luego, no estará en la validez científica de cada una de sus fuentes, sino en la orientación transformadora que comparten y que descorre el velo de neutralidad objetivista con que se

I Teoría tradicional y teoría crítica, traducción de José Luis López y López de Lizaga, introducción de Jacobo Muñoz, Barcelona: Paidós, 2000, p. 62. 
aproximan los estudios puramente analíticos e instrumentalizados. Si fuese un simple desarrollo de la ideología marxista de alguna dictadura del siglo XX, no cabría en su interior la inquietud epistemológica que preocupa a Horkheimer, pues bastaría con subsumir las condiciones de la investigación científica bajo la utilidad gubernamental. Los de Frankfurt, desde su exilio americano, expusieron que las circunstancias históricas presentes no son los únicos factores que regulan la tarea ético-política. Dicho quehacer se apoya en una teoría continente de juicios de valor que, por su parte, siempre apunta a un fin, y hacia éste mueve su esperanza. La siguiente presentación argumentará que la dúctil esperanza que se modeló en la primera etapa de la Escuela luce en su exterior un reclamo inmanente a la sociedad, pero tiene como argumento una singular teoría del conocimiento.

\section{§ 1. La posibilidad de la teoría crítica}

La forma más notoriamente censurada de teoría tradicional es la defendida por el positivismo. Hijas de la modernidad, sus formas de ciencia al iniciar el siglo $X X$ son ejemplarmente definidas por el físico Poincaré como un ordenamiento de enunciados sin contradicciones ni dogmatismos en sus conexiones, desde premisas simples hacia deducciones complejas, aunque ese orden no sea el de la naturaleza. Con el fin de su unificación, la física actúa como el bibliotecario o patrón, y la matemática como su expresión regulada. La epistemología cartesiana, el dualismo de pensamiento y ser, dispone a un sujeto cognoscente delante de un objeto externo cognoscible, y la construcción que el primero elabore sobre el segundo, así como la contrastación empírica, se concibe como objetiva. Gracias al método científico moderno, se lograría una descripción y clasificación del mundo fiel a la situación en la realidad. Una teoría demuestra la solidez de su estructura cuando los enunciados agrupados permiten explicar y predecir los fenómenos naturales con exactitud. Por tanto, el propósito tradicional de la teoría es juzgar imparcialmente al objeto externo: prepara su separación y retirada de toda circunstancia de interferencia, de manera que no tiene un fin u orientación en sí misma -sólo lo mantiene en tanto análisis minucioso del objeto aislado. Horkheimer se pregunta si es cierto que esta caracterización acrítica y autónoma respecto del mundo empírico pueda ser el sistema natural del conocimiento humano, cuestión que se decide dependiendo de cuán externa o separada de la situación de la realidad social se 
halle una teoría delimitada por el criterio postivista. Las disciplinas científicas no se consideran a sí mismas como actividades humanas pertenecientes al dinamismo de las relaciones sociales, vórtice de fines que ligan al actor con su objeto; más bien, su divisa es que sus objetos de estudio concentren todos sus fines -y éste es el origen del instrumento científico como asistente velado en la experimentación y la conclusión, y como útil industrial-, vale decir, que las teorías emerjan sin una conexión de intereses con el estado de la experiencia que la propició. Evidentemente, la separación entre el saber (la teoría) y el actuar (la praxis) es una garantía para tener los hechos circunscritos en un marco de conocimiento, así como un encubrimiento de que sus proposiciones son hipótesis que se corroboran sólo dentro de aquel marco y no universalmente, valiéndose de la neutralidad del científico y sus instrumentos.

Las consecuencias del pretendido trabajo del científico fuera de la esfera de la práctica y la sociedad son la creencia en una "trascendencia" o eternidad de su labor y, junto a ella, el fatalismo o la absoluta asimilación y conformidad con el orden de la realidad descrito. Mas la historia de la ciencia moderna no ha omitido en sus campos de estudio la comprobación de aquellas dos imponentes consecuencias. $Y$ es que la condición mudable de la sociedad y el pensamiento, en oposición al progresivo afianzamiento de las ciencias naturales, se presentaba como una limitación para la "perennidad" de la ciencia que se ocupara de aquellas. Ni siquiera la ciencia positivista, fiada solamente de las experiencias científicas, renunció al estudio de la sociedad. Si en el origen de la teoría tradicional, el sujeto autónomo, que es fundamento del saber, busca la coincidencia con el objeto exterior, ¿qué condiciones extrañas a la teoría modifican indefectiblemente la aproximación científica tradicional? Los encuentros entre cognoscente y cognoscible cambian, si no en la lógica trascendente, sí en la historia inmanente. Horkheimer extiende la posición de Marx: también el objetivo al que apuntan las ciencias, aquél que atiende meramente al objeto y no al investigador, surge de la historia, del orden social del presente. El comportamiento mecánico respecto de las transacciones materiales en la sociedad burguesa aprovecha la "imperecedera" teoría tradicional como poder de sustentación de su particular manejo de las relaciones sociales -particular, ya que históricamente recién nace en el siglo XVI. No se trata de una simple analogía o emparejamiento al azar entre la teoría y el orden social establecido; es el esclarecimiento de que en el capitalismo 
tardío aun la investigación científica más pura se paga y se somete a las reglas económicas, y que el mecanicismo de sus dicta económicos vuelve pasivos, desinteresados y sencillamente calculadores y previsibles a quienes deberían encarnar la fuerza crítica de la razón.

\section{§ 2. La insuficiencia de las ciencias "críticas" de la sociedad}

El desentrañamiento del sustrato social de la ciencia, la "sociología del saber" - "estudio de las ideologías"2, es el móvil que relativiza por necesidad la teoría tradicional y avanza por el camino de una teoría que contenga la totalidad histórico-social. Luego, debe saberse cómo las ciencias tradicionales, con su propósito de descubrir la totalidad mediante su método científico, han compensado su verdadera relatividad del conocimiento de la sociedad con un estudio que intente ser absoluto. Se trata de descubrir cómo el pensamiento crítico de la sociedad durante la modernidad tardía ha abordado los fundamentos de su supuesta objetividad y cómo, de acuerdo a la postura marxiana, sigue siendo, a su pesar, "ideología”.

A inicios del siglo $X X$, la sociología positivista iniciada por Comte, que debía descubrir con exactitud la dinámica trascendental que gobierna el pasaje de los estados de la sociedad, afronta el problema de determinar qué teoría se puede extraer de la realidad inmanente que es el cambio social. Las teorías darwinistas de Spencer, una suerte de determinismo que regulaba no sólo las edades geológicas sino las civilizaciones, son objetadas por Pareto, quien señala la irracionalidad o el subjetivismo -la pérdida de certidumbre de los puros datos empíricos con relación a las creencias de los individuos- en los ascensos y caídas de las élites. Progresivamente, la clave de esta contingencia se discernirá en los individuos mismos y no en un conglomerado sin pensamientos propios. De esta manera, la interpretación de la subordinación de las ideas del individuo a las de la sociedad se tornará en la meta del estudio empírico de la sociología; la crítica del segmentarismo científico prospera en el subjetivismo de la sociología. Durkheim entiende la sociedad cual una regularidad insondable más allá de la coerción hacia el individuo, mientras Weber 
sí cree en la comprensión del colectivo social de un modo espiritual -una dimensión política de las ideologías compartidas socialmente- evidenciada en la creciente racionalización y burocratización de las sociedades y Estados. Igualmente importante es la aparición del psicoanálisis como afirmación del sujeto cognoscente en tanto enriquecedor, por la praxis, de la experiencia social, y no al contrario ${ }^{3}$. Sentencia Adorno que el positivismo fue útil para la correcta comparabilidad y correlación entre los resultados empíricos, tal y como la reciente sociología antipositivista detecta las ideologías como manifestaciones de los individuos, inhibiéndose de confrontar sus opiniones con la organización real y las relaciones laborales en que se hallan. El estudio social teme llenar su tabula rasa con valores que no provengan de su tipo de constatación científica -la comprensión weberiana del capitalismo en tanto derivado de una ética planificada-, que está amparada en el carácter ineludiblemente neutro del subjetivismo ${ }^{4}$.

Por estos reparos, la sociología reciente todavía se gobierna por el dualismo epistemológico, sin asir como objeto a la totalidad humana, apartándose de la pregunta comprometedora por el valor ético-social de su ciencia. Entre las otras visiones "críticas" de la ciencia, tampoco el pragmatismo o la Escuela de Marburgo han conseguido juntar el trabajo científico con la realidad de su producción social a partir de una división del trabajo, suprimiéndole todo sentido que relacione al científico con una condición laboral en la sociedad. Aíslan la teoría del dinamismo social: la primera, por concebir la utilidad como externa a la teoría, desconectando los hechos; la segunda, por disolver todo lo empíricamente observable en categorías absolutas ${ }^{5}$.

La crítica se extiende ad initium, a la misma consagración de la teoría y la herencia de su estatus social por tradición. Desde su concepción aristotélica como la actividad más elevada del hombre que, a diferencia del saber práctico, es necesario y libre, y un fin por sí mismo, la ciencia moderna se orientó sólo a la acumulación del saber, y su configuración ignoró su posición en la infraestructura social, motivada por el olvido de las raíces históricas y productoras

3 Cf. Adorno, Theodor, Epistemología y ciencias sociales, traducción de Vicente Gómez, Madrid: Cátedra, 200I, p. 32.

4 Cf. ibid., pp. 99-102.

5 Cf. Horkheimer, Max, op. cit., pp. 31, 33. 
de la investigación: las definiciones nuevas siempre se deben también a una meta fijada desde fuera de la ciencia, y la comprobación de las hipótesis está, asimismo, mediada por la industria ${ }^{6}$.

Así, el modelo lógico de la razón separada de la praxis es incapaz de encargarse de la totalidad y de la historia, personajes que Marx transmuta en escenarios. La mencionada "trascendencia" de las proposiciones sesga a la teoría tradicional $y$, de una manera más tendenciosa, la convence de enmarcar la complejidad desde su propio reducto epistemológico.

\section{§ 3. La gestación de la teoría crítica}

¿Escoger un punto de partida de la ciencia desde la misma situación de las relaciones sociales, es decir, inmanentemente, equivale a una reflexión ajena a la tradición filosófica que parece haber sido la comparsa en la que secundaba a la razón naturalista? La tesis de Horkheimer es que, por su misma emergencia ante el caos social evidente y por su análisis marxiano desde las únicas causas que explican el desorden, la teoría crítica es una consecuencia de la tradición filosófica, con la singularidad de esclarecer la relación entre sujeto y objeto a partir del estudio de la sociedad, productora de todas las disciplinas. El rechazo de la verdad como adecuación, de la razón más allá del mundo, no debe tomarse como un dogma acerca de la "nueva trascendencia" de las leyes económicas que gobiernan la sociedad. Más bien, es la búsqueda de conocimiento de sí mismo desde la crítica de las instancias antes tenidas por intangibles, y hacia una práctica social que haga valiosa la teoría descubierta, contestando y confrontándose con las leyes económicas antedichas.

El cuestionamiento de la teoría crítica empieza con el punto central de la epistemología moderna: la discrepancia o coincidencia entre hechos y teorías. Kant criticó el dogmatismo científico, pero su explicación de la relación sujetoobjeto sólo trasladó el problema de la aproximación hacia los objetos a una esfera libre del movimiento de la praxis, unificando a ambos sólo fuera del mundo, o después de la conceptualización del saber. Que la tesis de habilitación 
de Horkheimer fuese La Crítica de la facultad de juzgar como mediación entre filosofía práctica y teórica conduce a entender el nuevo sentido de "crítica", en tanto conciliación y trabajo desde el mundo. El antiguo problema de la unidad sistemática de la filosofía trascendental fue solucionado por Kant con el esquematismo y el simbolismo, la correspondencia y la analogía entre intuición y concepto, respectivamente. El juicio teleológico las contiene, revirtiendo el esquema y el símbolo como el haz y el envés, según la intuición deba ser captada a través del tiempo como concepto o como reflexión ${ }^{7}$. La complicación de esta doctrina, junto a la indiferencia sobre la reflexión o la analogía simbólica que pueda hacerse del movimiento mismo de la historia, le cierra la vía a intuir el por qué el proceso social establece un acuerdo entre individuos sobre los conceptos -amén de la "consciencia en sí", no orientada a fines y supraindividual, que Kant arguye. De esta manera, refrenda la diferencia de percepción de los fenómenos entre el individuoy la sociedad como consecuencia de alejar el eje de la relación sujeto-objeto en una subjetividad trascendental. El idealismo abrirá las esclusas para pensar la sociedad como activa y pujante, compuesta de individuos, si bien mantiene la "pureza" o distanciamiento de la realidad del objetivo final del desarrollo humano ${ }^{8}$.

¿Cuál es el defecto del idealismo respecto del dualismo de la relación sujetoobjeto? La actividad social en tanto "espiritual" y racionalmente conducida reduce lo caótico de las relaciones sociales. Pero trunca su análisis de los objetos como concepciones que surgen de la sociedad, guiando a la praxis humana por el sendero de la "subjetividad universal" con miras al saber absoluto -desde antes del establecimiento de la sociedad y las ciencias particulares-, eventualmente extraño a la situación particular de los individuos. La extrañeza que causa el método dialéctico que conduce a un despliegue racional que trasciende al estado de la sociedad, utiliza, sin embargo, este distanciamiento para imprimir una negatividad -en términos sociales, una crítica-al pensamiento. La carencia hegeliana es la pretensión de que, pese al estado de negación en la dialéctica, la lógica universal mantiene la identidad con los momentos históricamente concretos: el orden establecido en la sociedad,

7 Cf. Albizu, Edgardo, "La Crítica de la Facultad Discretiva y la unidad sistemática de la filosofía trascendental”, en: Sobrevilla, David (comp.), Filosofía, política y estética en la crítica del juicio de Kant, Lima: Instituto Goethe, 199I, pp. 24-25.

8 Cf. Horkheimer, Max, op. cit., pp. 37-39. 
a pesar de sus contradicciones, es racional y un fin para la razón`. Si es que se atiene al análisis del momento de la sociedad, la conformidad con aquél es la supresión del impulso transformador de la negatividad en la dialéctica.

El giro marxiano, el hallazgo del dinamismo humano no en el espíritu, sino en el trabajo, implica la crítica a la teoría tradicional y la filosofía "especulativa" sin tomar en cuenta la "conciencia más allá de lo empírico", la respuesta secular a la coincidencia entre el sujeto y el objeto y la autonomía del individuo ante la sociedad. La sospecha se acrecienta cuando revela la manera en que esta respuesta y cualquier otra posibilidad de solución son generadas a partir de la división social del trabajo. Luego, si cada teoría se relaciona con el fin determinado de una época, la respuesta de la filosofía moderna no puede ser desinteresada ni mucho menos sempiterna. La dimensión anterior a toda gesta científica enfoca los esfuerzos del saber hasta ahora acumulado a buscar la emancipación, el compromiso abierto con la sociedad y no su acallamiento. Los epígonos de la teoría de Marx subrayarán el carácter reflexivo y proyectivo de la investigación social, puesto que en ella, en la reflexión sobre uno mismo y las condiciones en que se halla y tiene la posibilidad de transformar, se encuentran el sujeto y el objeto al mismo tiempo ${ }^{10}$.

Los intereses oscilantes de los trabajos de Marx, quien dejaría inconclusa o inédita gran parte de su obra al morir, no muestran la implicancia social de la dialéctica más allá de la crítica de la economía política. En contraste, los escritos de seguidores que comenzaron a interpretar el pensamiento del joven Marx junto a Hegel y la tradición filosófica de la crítica y a considerar el método dialéctico como integral para una solución más general, consideraron la construcción de una teoría social que no esté disminuida por un concepto unilateral de la razón". Fundamentalmente, Lukács proclama la "ortodoxia" de su marxismo, es decir, la aplicación de la dialéctica para conocer la realidad total, sin caer en una minusvaloración del método de la "clasificación científica" de los conceptos socio-económicos hecha por los supuestos ortodoxos. Un pensador

9 Cf. Cortina, Adela, op. cit., p. 42.

10 Cf. Walzer, Michael, Interpretation and Social Criticism, Cambridge: Harvard University Press, 1993, p. 35. Cambridge: Polity Press, 1986, pp. 38, 178. 
marxiano debe renunciar al fatalismo de las ciencias sociales y encargarse de los fines humanos que son el aliento para el cambio. Sin embargo, Lukács examina que la inacción o inhabilidad de reconocerse como transformador parte de una mecanización universal que ha formado la conciencia del sujeto de modo que sus deberes le son tan extraños como el fondo histórico en que se sitúa. Y, debido a que Marx no determina las clases según sus posiciones en el proceso de producción en El capital, no se aclara si sus consciencias son explorables por el estudio de las características en la sociología empírica, o pertenecen a la teoría general marxista ${ }^{12}$. Pertinentemente, Lukács articula la consciencia de clase como la reacción racionalmente adecuada que una clase económica desarrolla en tanto momento del proceso de producción, inculcándose una forma de vida limitada por la repetición de su trabajo pero, al mismo tiempo, posibilitando que su crítica sea la crítica de la totalidad de su forma de existencia. El fenómeno que unifica y se repite incesantemente en el proletariado es la cosificación: en las relaciones interpersonales se identifica al individuo con la estructura de la mercancía, apareciendo como regido por las leyes del cálculo económico y, también, con la imagen de haber obtenido su "esencia", mas no viviéndola, sólo viéndola pasar'³. La cosificación, por su carácter de reproducción constante es la marca del capitalismo tardío para Lukács, de modo que se decanta y se convierte en el hormigón de sus cimientos, sosteniendo su basamento, que es el poder del capital. El resto de la columna se fabrica en regla con el sostén, su sistema de necesidades y valores es automatizado y "racionalmente estabilizado".

En su lección inaugural del Instituto de Investigación Social, Horkheimer confía en que la solución de la conciliación entre la razón general de la sociedad y la individual se logre por la unión de la filosofía y las ciencias empíricas, posibilitada por la teoría de Marx: sociología, economía, historia y psicología, si se reúnen, han de concluir necesariamente en herramienta y justificación para el cambio hacia un orden social más humano' ${ }^{14}$. La teoría guía a las ciencias, no desde fuera -por ejemplo, en la metafísica hegeliana-, sino desde sus más pequeñas intenciones descubridoras y preceptos metodológicos. La filosofía inherente

${ }^{12}$ Cf. Lukács, György, Historia y conciencia de clase: estudios de dialéctica marxista con un nuevo prólogo del autor, traducción de Manuel Sacristán, México, D.F.: Grijalbo, 1969, pp. 42, 49.

${ }^{13}$ Cf. ibid., pp. 90, 95, 96.

${ }^{14}$ Cf, Wiggershaus, Rolf, op. cit., pp. 38-40. 
al pensamiento de Marx vuelve a un primer plano con Horkheimer, antes que la descripción de las leyes económicas. La depuración de Lukács y el retorno a los orígenes críticos lo lleva, de esta manera, a una contrastación universal con todas las ciencias portadoras de datos de relevancia social.

\section{§ 4. Las características de la teoría crítica}

El derrotero de Horkheimer que se trasluce en Teoría tradicional y teoría crítica tiene como antecedente directo el conjunto de ensayos Autoridad y familia, paradigmático en cuanto a la combinación de experimentación, descripción y examen crítico del individuo y la sociedad. Su partida es la polivalencia del concepto de autoridad -que recorre todos los momentos históricos posibilitando la confluencia de los individuos y, por eso mismo, no es definible en general porque su aparición concreta siempre es un producto de la situación histórica- y la familia como centro de reproducción de las formas consentidas de una cultura. Ambas unen la historia, la economía y la psicología de los hombres por medio de un artificio al que se imagina "natural"15. La naturaleza del hombre, su esencia, es la práctica histórica, no la cultura que se haya validado en determinada época: ése es su movimiento real. La forma particular de autoridad en el mundo burgués representó el papel del resultado de la naturaleza "en su avance racional". Incluso las críticas que se hicieron al liberalismo sin tomar en cuenta aquella impostura pecan de aislarse del mundo y representar, irónicamente, el rol de la libertad auténtica, en oposición a la opresión de las formas del capitalismo. La contradicción, para Horkheimer, es una restricción para las disciplinas científicas, no para la teoría crítica. Con su plasmación y reproducción en la familia, la autoridad de la burguesía finiquitaría su camuflaje con los rasgos del padre imponiendo su autoridad, un recurso entendiblemente natural para fundar la jerarquía social a perpetuidad para las conciencias acríticas ${ }^{16}$.

${ }_{15}$ Cf. Ferrarotti, Franco, El pensamiento sociológico de Auguste Comte a Max Horkheimer, traducción y notas de Carlos M. Rama, Barcelona: Península, 1975, pp. 218-219. 
La vocación de Horkheimer por aprehender la totalidad compleja, gracias a la contribución de Marxy las ciencias socio-empíricas, se distinguió del programa interpretativo y acucioso en distintos campos de la cultura de Adorno por remarcar el carácter no teleológico y socialmente determinado que la razón les ofrecía respecto de la situación del presente histórico limitado ${ }^{17}$. Es lícito preguntarse si en algún momento del delineamiento de su teoría, su epistemología se apartó lo suficiente de lo empíricamente comprobable para dar el indeseado salto hacia una metafísica pesimista del solitario autoconocimiento de la teoría. Lo que es cierto es que sus trabajos tempranos son animados por la condena moral al sistema de valores y de conocimiento único que impone la burguesía, y la elaboración de una teoría dialécticamente válida y libre de su corrupción, que es inevitable para fundamentar su crítica de la economía.

La tensión entre el aspecto lógico y el valorativo del conocimiento es observable en Teoría tradicional y teoría crítica. El eje de la crítica es el concepto de actitud (Verhalten) del hombre, un distanciamiento de la razón moderna de cálculos, cifrado en la comprensión de la sociedad como un todo viviente explicable por la dialéctica ${ }^{18}$. El estudio del todo la estimula a analizar y proyectar los fines u objetivos de su voluntad éticamente responsable dentro de todas las experiencias, científicas y no científicas. La separación entre individuo y sociedad es relativizada por la desconfianza en los órdenes vigentes que ésta ha impuesto, y ello prepara la pérdida de trascendencia de las proposiciones científicas. ¿Y qué conduce a la formación de tal actitud radicalmente crítica? La teoría marxiana de la división social del trabajo y las contradicciones entre las clases como acicate para la instauración del orden racional de la dialéctica no es gratuita en la filosofía de Horkheimer. La unidad trascendental del conocimiento, afirmada por Kant, no había de ser demostrable en la historia por categorías que unieran a la conciencia la posibilidad de escapar del determinismo, hasta que Marx colocó la única objetividad en el estado actual de la sociedad. Consecuentemente, ello elimina el dilema entre cognoscente pasivo-conocido activo y cognoscente activo-conocido pasivo, pues descosifica lo que nunca antes se pensó que fuera un objeto del mundo, la teoría, y dispone a sujeto y objeto como copartícipes de un juego de sojuzgamiento

${ }_{17}$ Cf. Wiggershaus, Rolf, op. cit., p. 180.

${ }^{18}$ Cf. Horkheimer, Max, op. cit., pp. 4I-42. 
y de posibilidades completas de liberación. Incluso la imprevista teoría de Copérnico no se habría reconocido sólo por la revisión entre proposiciones lógicas, sino que es principiada por el mecanicismo que, proveniente de las relaciones sociales, se colaba entre las cribas de la Nueva Ciencia' ${ }^{19}$. La particularidad del capitalismo avanzado es el descarrío de la misma objetividad científica que piensa servir al bien de la ciencia acrecentando sus usos en la vida cotidiana por medio de la industria, sin colegir que ello mismo es un proceso social y que el trabajo de los científicos está subvencionado por los intereses del capital. El procedimiento de la crítica es revelar la parcialidad científica, exponiendo que lo que llama "objeto" no se agota en la descripción teorética o intencional de ninguna disciplina o discurso en solitario, pues ninguna es capaz de indicar la organicidad de aquél con el conjunto total de la sociedad ${ }^{20}$. La equivalencia entre poseer fines sociales y sistematicidad salva a la segunda del idealismo decimonónico.

¿Y qué queda de la experiencia científica en la teoría crítica? La recoge y clasifica como las ciencias tradicionales. Con todo, su actitud verifica que el interés de los individuos despierta los movimientos sociales. De aquí se desprende la desconfianza de la teoría crítica en la acción del proletariado, sujeto clásico de la revolución marxista, y de la intelligentsia que divaga entre utopías sociales. Los proletarios experimentan actos sociales extraños a su auténtica conciencia -el descubrimiento de sus particulares relaciones de trabajo como generadores de su conducta social-, sus miembros disienten entre sí y sus ideas son falseadas continuamente por la burguesía ${ }^{21}$. Walzer apunta que la crítica irá, en primer lugar, contra la clase proletaria -antes que la burguesía - para enrostrarle su ideología subyugada y deformada y, también, su estéril habilidad para emanciparse y enarbolar valores humanos y "reales"22. La experiencia cambia la función de la crítica en cuanto tal: no es un "momento" del transcurrir histórico ni se reduce al entendimiento común de toda una comunidad. La teoría aborda -entiéndase a la usanza científica tradicional, es decir, como "objeto"- la realidad que el sujeto crítico concibe, y la coincidencia entre saber y actuar está forzosamente proyectada hacia el

${ }^{19}$ Cf. ibid., pp. 29-30.

${ }^{20}$ Cf. ibid., p. 34.

${ }^{21}$ Cf. ibid., pp. 46-48.

$84{ }^{22}$ Cf. Walzer, Michael, op. cit., p. 57. 
futuro, por las intenciones ${ }^{23}$. Puede acusársele de inútil o improductiva; no obstante, en su resiliencia está su esfuerzo por una educación del hombre mantenida en el tiempo, más que el adoctrinamiento.

El otro lado, su aspecto lógico, se caracteriza por asemejarse a la teoría tradicional, en tanto que sus conceptos son determinaciones abstraídas de la experiencia, y se distingue por la relación de intercambio fructífero del concepto con la experiencia, avalada por la relativización de la historia y de la economía. Asimismo, comparten la deducción por necesidad, pero mientras la teoría tradicional se confina en las hipótesis, la crítica desarrolla juicios desplegados sobre la existencia general, ya que observa que de sus juicios sobre la acumulación de interés del capital se deducen juicios sobre la historia ${ }^{24}$. La teoría crítica no constriñe a la tradicional, solamente la relativiza en la historia. Así, ella puede particularizarse sin desmedro de quitarle la valoración a la sucesión de hechos que capte y describa. Horkheimer se distancia del materialismo histórico de Marx que asigna tipos de pensamiento a un periodo histórico, surgidos de sus relaciones de producción; su concepto de juicio existencial de la totalidad está él mismo condicionado a aparecer de la manera que le dicte un periodo histórico y no a la inversa, pues la sociedad es concomitante con los cambios de relaciones económicas ${ }^{25}$. Su análisis crítico, sin embargo, sí realiza la crítica del capitalismo desde la manera como él mismo definió sus reglas en la historia: contrapone el capitalismo productivo de los albores del liberalismo, signado por la propiedad jurídica, al capitalismo parasitario, también llamado tardío o monopolista, que agiganta los poderes sociales que inutilizan las propiedades menores ${ }^{26}$.

Fijada la actitud lógica y experimental en la teoría crítica, sólo resta entender cómo transformará. No mediante la mera manifestación teórica, sino emplazando a la voluntad a seguirla porque es su interés. Claramente, Horkheimer no podría asentar su obra sobre fundamentos fijos, que no servirían para conectar el conocimiento con la praxis, sino sobre proposiciones vinculantes entre tareas de la sociedad, que avancen en una crítica compartida contra las

${ }^{23}$ Cf. Horkheimer, Max, op. cit., p. $5 \mathrm{I}$.

${ }^{24}$ Cf. ibid., pp. 6I-63.

${ }^{25}$ Cf. ibid., pp. 68-69.

${ }^{26}$ Cf. ibid., pp. 70-7I. 
formas opresoras y persiguiendo el único fin de la totalidad, que es la liberación y la dignidad plenamente vivida ${ }^{27}$. Este modo excepcional de validación de la teoría, a la medida de cada estrato y tiempo de la historia, tendría como única prescripción a la dialéctica que acerca la epistemología a la axiología y la ética. Sin usar una fórmula universal, el individuo no se enfrenta destructivamente a la sociedad, sino que se integra a ella de una manera nueva, la emancipadora, si bien hostil para la "neutralidad" de la ciencia y el poder con que convive.

\section{\$ 5. Las objeciones al enfoque epistemológico-axiológico de la teoría crítica}

Como escribe Horkheimer en el Apéndice a su obra, el mayor riesgo sería la identificación entre la crítica del conocimiento y la asunción de que todo el conocimiento proviene del esclarecimiento del segmento económico de la totalidad de la ciencia. Es cierto que la teoría crítica emplea las categorías económicas y las encaja en la sociedad -que es su auténtica fuente de conocimiento-, pero reconoce que la praxis sobrepasa al economicismo. Como en Marx, el hombre no es reductible a sus posibilidades materiales, pues ello haría de la teoría crítica un mecanicismo meta-positivista. Su cometido de regenerar la totalidad no se lograría con la visión estática o progresiva de la historia, sino con la asignación extraeconómica de una dirección ${ }^{28}$. Otra confusión surgiría de empaquetarla con la psicología social, que formula las ideas de los individuos de un sector. La teoría crítica no queda en una descripción, debido a que indaga en la contradicción entre los sujetos para unificar las concepciones de cada uno de ellos con el sustrato social al que pertenecen por medio de la proyección y realización de sus intereses.

Más grave es pensar en el derecho que tiene para llamarse "teoría" y no, muy a su pesar, "ideología". Comparte métodos experimentales y lógicos con las teorías tradicionales, pero la distancia su concepto de la historia como activa y viva y el impulso de la valorización en las ciencias. Poco puede defendérsele si se restringe el término a los ingenios que describen acertadamente 
el funcionamiento discreto de la realidad para que correspondan con lo observable. Sin embargo, como se repasó, esta perspectiva olvida dos cosas: que los mismos instrumentos son guías interesados del trabajo científico -y el origen de sus intereses sólo se ve a través de la historia-y que incluso el positivismo, si le conciernen puramente los hechos, se ve en la paradoja de "criticar" constantemente la implicación del científico y sus intereses en cada experimento, hasta que advierte que son indesligables.

Por último, las tendencias de distintas generaciones y personalidades de la Escuela ante la posición original de Horkheimer son sintetizadas por Honneth así: Horkheimer desliga subrepticiamente a la teoría tradicional de todos los procesos sociales de producción, pese a su confesión de que es un "momento" del esclarecimiento dialéctico que, por tanto, debe tener alguna conciencia histórica. Esto es, le resta el soporte de una filosofía de la historia a la teoría tradicional para adjudicárselo a su teoría crítica que, de por sí, requiere de un hiato o distancia crítica que se soluciona complicadamente, pues, para avistar el futuro, la praxis necesita las luces de una "trascendencia"29. Aunque la objeción de Honneth es válida, tras revisar los problemas que sufre Horkheimer para, siempre distanciándose de las respuestas anteriores, infundir en el cognoscente primero la pasividad y luego la actividad en la aproximación al objeto -y que visto por todos, no parezca perderse en la teoría-, recuérdese el espíritu exploratorio que se halla en Autoridad y familia. Las categorías que allí emplea son extensas, no se circunscriben. No se extiende su examen especulativo mientras no separe y clasifique los descubrimientos de las encuestas y estudios sociales pues no está delimitando un método; su finalidad es la exposición cromática de la riqueza empírica que conecta sus elementos y genera una praxis deseable al difuminarla en el plano total de la sociedad ${ }^{30}$.

${ }^{29}$ Cf. Honneth, Axel, Crítica del poder: fases en la reflexión de una teoría crítica de la sociedad, traducción e introducción de Germán Cano, Madrid: A. Machado Libros, 2009, 29-34.

${ }^{30}$ Cf. Ferrarotti, Franco, op. cit., pp. 234-235. 